\title{
Una aproximación de los derechos humanos de las mujeres a partir de una lectura hermenéutico- analógica-icónica de la historia de Tamar (2 Samuel 13:1-22)*
}

\author{
Gabriel Alfonso Suarez Medina** \\ José Luis Meza Rueda*** \\ Víctor Marciano Martínez Morales**** \\ Ana Meldivelso ${ }^{* * * *}$
}

Recibido: 19 de marzo de 2015 - Revisado: 6 de abril de 2015 -

Aprobado: 10 de abril de 2015

Una lectura, desde la perspectiva de la hermenéutica analógica-icónica, de 2 Samuel 13:1-22 puede contribuir a la transformación de la realidad personal y comunitaria, pero también al desarrollo de una reflexión teológica preocupada

* Este artículo es un avance de la investigación en curso "Aproximación teológica a la sexualidad, la salud reproductiva y los derechos humanos desde la investigación acción participativa. Lectura contextual de 2 Samuel 13:1-22", cofinanciada por la Iglesia Luterana Sueca y aprobada por la Pontificia Universidad Javeriana (ID. 00006554). DOI: http://dx.doi. org/10.15332/s0120-8454.2015.0087.02

** Licenciado en Educación, Filosofía y Letras de la Universidad Santo Tomás, teólogo de la Pontificia Universidad Salesiana de Roma, licenciado en Teología, Pontifica Universidad Javeriana; especialista en docencia universitaria de la Universidad Santo Tomás, Bogotá; doctor en Filosofía, Universidad Gregoriana de Roma. Profesor asociado e investigador en la Facultad de Teología de la Universidad Javeriana. Miembro del grupo de investigación Didaskalia. Dirección postal: Cra. 7 \# 40-62, Bogotá (Colombia), correo electrónico: gs000123@javeriana.edu.co

*** Doctor y magíster en Teología, Pontificia Universidad Javeriana; magíster en Docencia, Universidad de La Salle; especialista en Educación Sexual, FUM; especialista en Desarrollo Humano y Social, IPX-Madrid; licenciado en Educación con especialidad en Estudios Religiosos, Universidad de La Salle. Profesor asociado de la Facultad de Teología. Miembro del grupo de investigación Didaskalia. Dirección postal: Cra. 7 \# 40-62, Bogotá (Colombia), correo electrónico: joseluismeza@javeriana.edu.co

**** Licenciado en Filosofía y Letras, Pontificia Universidad Javeriana de Bogotá, magíster y licenciado en Teología por la misma Universidad. Doctor en Teología, Pontificia Universidad Gregoriana de Roma (1991). Profesor ordinario, titular e investigador de la Facultad de Teología de la Pontificia Universidad Javeriana. Miembro y director del grupo de investigación Didaskalia. Dirección postal: Cra. 7 \# 40-62, Bogotá (Colombia), correo electrónico: vicmar@javeriana. edu.co

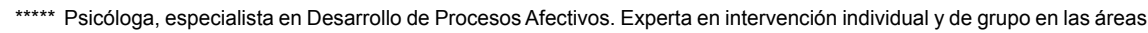
de salud, laboral y educativa. Terapeuta de pareja y familia. Directora de proyectos del Centro Apoyo y Referencia ASIVIDA. Dirección postal: Cra. 13 \# 55-56, correo electrónico: andan1409@hotmail.com 
por los derechos humanos de las personas en contextos vulnerables de la sociedad colombiana, cuyo tejido social ha sido rasgado por el conflicto armado y la violencia intrafamiliar. Se trata de una lectura que no se limita a legitimar discursos (lectura unívoca, dogmática) o simplemente acepta cualquier interpretación (lectura equívoca, relativista) según intereses individuales, sino que propone ir al contexto real de las situaciones para liberar las personas de sus estigmas y devolverlas a la sociedad capaces de empoderarse y autoagenciarse, porque proporciona mecanismos que les permiten hacer valer sus intereses de manera legítima, así como exigirles a las entidades gubernamentales que acaten los estándares de conducta a los que se han comprometido.

Palabras clave: hermenéutica analógica-icónica, derechos humanos de la mujer, historia de Tamar, Huellas de Arte. 


\title{
An approach to women's human rights from an analog-iconic hermeneutic reading of the story of Tamar (2 Samuel 13:1-22)*
}

\author{
Gabriel Alfonso Suarez Medina** \\ José Luis Meza Rueda** \\ Víctor Marciano Martínez Morales*** \\ Ana Meldivelso ${ }^{* * * *}$
}

A reading, from the perspective of the analog-iconic hermeneutics, of 2 Samuel 13: 1-22 can contribute to the transformation of personal and community reality, but also to the development of a theological reflection concerned about the human rights of people in vulnerable contexts of Colombian society, whose social fabric has been torn by armed conflict and domestic violence. This is a reading that is not limited to legitimize discourses (univocal reading, dogmatic) or simply accept any interpretation (misreading, relativistic) according to individual interests, but it proposes going to the actual context of the situations to free people from their stigmas and return them to society able to empower

* This article is a preview of the ongoing investigation "theological approach to sexuality, reproductive health and human rights from participatory action research. Contextual reading of 2 Samuel 13: 1-22 ", financed by the Swedish Lutheran Church and approved by the Pontificia Universidad Javeriana (ID 00006554.).

** Degree in Education, Philosophy and Letters of the University of St. Thomas, theologian of the Pontifical Salesian University of Rome, graduated in Theology, Pontificia Universidad Javeriana; specialist university teaching of St. Thomas University, Bogota; Doctor of Philosophy, Gregorian University in Rome. Associate professor and researcher at the Faculty of Theology at the Javeriana University. Member of the research group Didaskalia. Address: Cra 7 \# 40-62, Bogota (Colombia), e-mail: gs000123@javeriana.edu.co

*** Doctor and Master of Theology, Pontificia Universidad Javeriana; MA in Teaching, University of La Salle; Sexual Education specialist, LMP; Specialist in Human and Social Development, IPX-Madrid; degree in Education with specialization in Religious Studies, University of La Salle. Associate Professor of the Faculty of Theology. Member of the research group Didaskalia. Address: Cra 7 \# 40-62, Bogota (Colombia), e-mail: joseluismeza@javeriana.edu.co

**** Degree in Philosophy, Pontificia Universidad Javeriana, master's degree in theology from the same university. Doctor of Theology, Pontifical Gregorian University in Rome (1991). Ordinary professor and researcher at the Faculty of Theology at the Pontificia Universidad Javeriana. Member and director of the research group Didaskalia. Address: Cra 7 \# 40-62, Bogota (Colombia), e-mail: vicmar@javeriana.edu.co

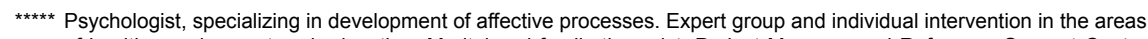
of health, employment and education. Marital and family therapist. Project Manager and Reference Support Center ASIVIDA. Address: Cra 13 \# 55-56, e-mail: andan1409@hotmail.com 
themselves and self-manage because it provides mechanisms that allow them to assert their interests legitimately, and demand government entities to abide by standards of conduct to which they are committed.

Keywords: Analog-iconic hermeneutics, women's human rights, story of Tamar, Footprints of Art, community of inquiry. 


\title{
Une approche aux droits de l'homme des femmes à partir d'une lecture hermémeutico-analogico- iconique de l'histoire de Tamar (2 Samuel 13:1-22)*
}

\author{
Gabriel Alfonso Suarez Medina** \\ José Luis Meza Rueda*** \\ Víctor Marciano Martínez Morales**** \\ Ana Meldivelso****
}

Une lecture, à partir de la perspective de l'herméneutique analogico-iconique, de 2 Samuel 13:1-22 peut contribuer à la transformation de la réalité personnelle et collective, mais aussi au développement d'une réflexion théologique qui s'inquiète des droits de l'homme des personnes en situation vulnérable dans la société colombienne, dont le tissu social a été brisé para le conflit armé et la violence domestique. Il s'agit d'une lecture qui ne se limite pas à légitimer des discours (lecture univoque, dogmatique) ou qui simplement accepte n'importe quelle interprétation (lecture équivoque, relativiste) celon des intérêts individuels, mais qui propose d'aller vers le contexte réel des situations pour libérer

* Cet article est un aperçu de l'enquête en cours "d'approche théologique de la sexualité, la santé reproductive et les droits humains de la recherche-action participative. Lecture contextuelle de 2 Samuel 13: 1-22 ", financé par l'Eglise luthérienne suédoise et approuvé par la Pontificia Universidad Javeriana (ID 00006554.).

** Diplôme en éducation, Philosophie et Lettres de I'Université de St. Thomas, théologien de I'Université pontificale salésienne de Rome, diplômé en théologie, Pontificia Universidad Javeriana; l'enseignement universitaire spécialiste de l'Université St. Thomas, Bogota; Docteur en Philosophie, Université Grégorienne de Rome. Professeur agrégé et chercheur à la Faculté de Théologie de l'Université Javeriana. Membre du groupe de recherche Didaskalia. Adresse: Cra 7 \# 40-62, Bogota (Colombie), e-mail: gs000123@javeriana.edu.co

*** Docteur et maître de théologie, Pontificia Universidad Javeriana; MA en enseignement de I'Université de La Salle; Spécialiste de l'éducation sexuelle, LMP; Spécialiste en développement humain et social, IPX-Madrid; diplôme en éducation avec spécialisation en études religieuses, Université de La Salle. Professeur agrégé de la Faculté de théologie. Membre du groupe de recherche Didaskalia. Adresse: Cra 7 \# 40-62, Bogota (Colombie), e-mail: joseluismeza@ javeriana.edu.co

**** Licence de Philosophie, Pontificia Universidad Javeriana, une maîtrise en théologie de la même université. Docteur en théologie de l'Université pontificale grégorienne à Rome (1991). Professeur ordinaire et chercheur à la Faculté de théologie de la Pontificia Universidad Javeriana. Membre et directeur du groupe de recherche Didaskalia. Adresse: Cra 7 \# 40-62, Bogota (Colombie), e-mail: vicmar@javeriana.edu.co

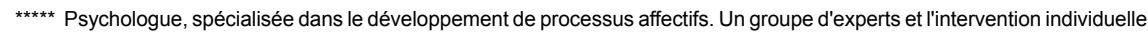
dans les domaines de la santé, l'emploi et l'éducation. Thérapeute conjugal et familial. Chef de projet et de référence Support Center ASIVIDA. Adresse: Cra 13 \# 55-56, e-mail: andan1409@hotmail.com 
les personnes de leurs stigmates et de les rendre à la société capables de prendre leur pouvoir en main et de s'auto-diriger, parce qu'elle propose des mécanismes qui leur permettent de faire valoir leurs intérêts de manière légitime et d'exiger également aux entités gouvernementales de respecter les standards de conduite auxquels elles se sont engagées.

Mots clés: Herméneutique analogico-iconique, droits de l'homme de la femme, histoire de Tamar, Empreintes d'art. 


\section{Introducción}

En el desarrollo de la investigación "Aproximación teológica a la sexualidad, la salud reproductiva y los derechos humanos desde la investigación acción participativa. Lectura contextual de 2 Samuel 13:1-22", hemos considerado que una hermenéutica analógica-icónica del texto bíblico en cuestión puede contribuir a la transformación de la realidad personal y comunitaria, pero también al desarrollo de la reflexión teológica preocupada por los derechos humanos y de las personas que se encuentran en contextos vulnerables como es el caso de la sociedad colombiana.

La hermenéutica analógica-icónica permite una lectura que no se queda legitimando discursos (lectura unívoca, dogmática) o simplemente aceptando cualquier interpretación (lectura equívoca, relativista) según intereses individuales; sino que propone ir al contexto real en el cual suceden las situaciones para liberar las personas de sus estigmas y devolverlas a la sociedad como autogestoras de sus destinos.

Se trata de mostrar cómo la Sagrada Escritura y los derechos humanos sirven para ayudarles a los sujetos a empoderarse y autoagenciarse porque proporcionan mecanismos que les permiten hacer valer sus intereses de manera legítima; igualmente, los individuos pueden emplearlos para exigirles a las entidades gubernamentales que acaten los estándares de conducta a los cuales se han comprometido. El relato bíblico puede contribuir al restablecimiento de la confianza de las personas en sí mismas y a desarrollar su potencial como reconstructoras del tejido social, rasgado en Colombia por el conflicto armado y la violencia intrafamiliar.

El artículo se desarrolla en cuatro momentos. El primero, muestra una aproximación a la narrativa bíblica, con lo cual se busca evidenciar la decadencia de los metarrelatos y la vuelta a la narrativa. En un segundo momento, se evidencia la importancia de los derechos humanos como plataforma para exigir la dignidad de la persona. El tercer momento, evidencia algunas hermenéuticas bíblicas, de modo que el lector pueda identificarlas. Para finalmente, desde la hermenéutica analógica icónica, hacer una propuesta de lectura del texto de Tamar, donde se desprendan las posibilidades reales a las personas que han sido estigmatizadas de liberarse y autoagenciarse.

Es oportuno transcribir la historia de Tamar de modo que el lector tenga presente la narración que aparece en 2 Samuel 13:1-22 (Biblia de Jerusalén):

${ }^{1}$ Sucedió después que Absalón, hijo de David, tenía una hermana que era hermosa, llamada Tamar, y Amnón, hijo de David, se prendó de ella. ${ }^{2}$ Estaba Amnón tan atormentado que se puso enfermo, porque su hermana Tamar era virgen y le parecía difícil a Ammón hacerle algo. ${ }^{3}$ Tenía Amnón un amigo llamado Yonadab, hijo de Simá, hermano de David; era Yonadab hombre muy astuto, 
${ }^{4}$ y le dijo: “¿qué te sucede, hijo del rey, que de día en día estás más afligido? ¿No me lo vas a descubrir?”. Amnón le dijo: “estoy enamorado de Tamar, hermana de mi hermano Absalón". ${ }^{5} Y o n a d a b$ le dijo: "acuéstate en tu lecho y fíngete enfermo y cuando tu padre venga a verte le dices: que venga, por favor, mi hermana Tamar a darme de comer; que prepare delante de mí algún manjar para que lo vea yo y lo coma de su mano".

${ }^{6}$ Y Amnón se acostó fingiéndose enfermo. Entró el rey a verle y Amnón dijo al rey: "que venga, por favor, mi hermana Tamar y fría delante de mí un par de frituras y yo las comeré de su mano". ${ }^{7}$ David envió a decir a Tamar a su casa: "vete a casa de tu hermano Amnón y prepárale algo de comer". ${ }^{8}$ Fue, pues, Tamar a casa de su hermano, que estaba acostado; tomó harina, la amasó, hizo los pasteles y los puso a freír delante de su hermano; ${ }^{9}$ tomó la sartén y la vació delante de él, pero él no quiso comer; y dijo Amnón: "que salgan todos de aquí".

Y todos salieron de allí. ${ }^{10}$ Entonces Amnón dijo a Tamar: "tráeme la comida a la alcoba para que coma de tu mano". Tomó Tamar las frituras que había hecho, se las llevó a su hermano Amnón a la alcoba ${ }^{11} \mathrm{y}$ se las acercó para que comiese, pero él la sujetó y le dijo: "ven, acuéstate conmigo, hermana mía".

${ }^{12}$ Pero ella respondió: "no, hermano mío, no me fuerces, pues no se hace esto en Israel. No cometas esta infamia. ${ }^{13}$ ¿A dónde iría yo deshonrada? Y tú serías como un infame en Israel. Habla, te lo suplico, al rey, que no rehusará entregarme a ti". ${ }^{14}$ Pero él no quiso escucharla, sino que la sujetó y forzándola se acostó con ella.

${ }^{15}$ Después Amnón la aborreció con tan gran aborrecimiento que fue mayor su aborrecimiento que el amor con que la había amado. Y le dijo Amnón: "levántate y vete". ${ }^{16}$ Ella le dijo: "no, hermano mío, por favor, porque si me echas, este segundo mal es peor que el que me hiciste primero". Pero él no quiso escucharla. ${ }^{17}$ Llamó al criado que le servía y le dijo: "échame a esta fuera y cierra la puerta tras ella".

${ }^{18}$ Vestía ella una túnica con mangas, porque así vestían antes las hijas del rey que eran vírgenes. Su criado la hizo salir fuera y cerró la puerta tras ella. ${ }^{19}$ Tamar puso ceniza sobre su cabeza, rasgó la túnica de mangas que llevaba, puso sus manos sobre la cabeza y se iba gritando mientras caminaba.

${ }^{20} \mathrm{Su}$ hermano Absalón le dijo: “¿es que tu hermano Amnón ha estado contigo? Ahora calla, hermana mía; es tu hermano. No te preocupes de este asunto". Y Tamar quedó desolada en casa de su hermano Absalón. 
${ }^{21}$ Cuando el rey David supo todas estas cosas se irritó en extremo, pero no quiso castigar a su hijo Amnón, al que amaba porque era su primogénito. ${ }^{22}$ Absalón no dijo a Amnón ni una palabra, ni buena ni mala, pues odiaba Absalón a Amnón porque había humillado a su hermana Tamar".

\section{Aproximación a la narración bíblica}

Es evidente que hoy se pone en duda la legitimidad del conocimiento científico como único modo de validar los saberes o las disciplinas. De modo que se está recurriendo, cada vez más, a nuevas formas de abordar los problemas y las situaciones para que estas tengan otras miradas y enfoques que permitan un acercamiento a ellas. Lógicamente la teología no puede estar ajena a dichas situaciones que marcan un nuevo ritmo en el conocimiento.

Cuando la teología se contextualiza, empieza a valorar la cultura, la historia, las formas de pensamiento y otros aspectos por el estilo y, junto a la Escritura y la Tradición, son consideradas como fuentes válidas para la expresión teológica. En otras palabras, y como conclusión, podemos decir que cuando hablamos de teología, lo hacemos teniendo tres fuentes -o loci theologici-: Escritura, Tradición y Experiencia humana presente (o contexto) (Bevans, 2004, p. 22).

Lo cual indica que cada vez más se hace necesario volver a la experiencia humana, al mundo de la vida y del texto, se puede decir con Ricoeur (1975):

Lo que hay que interpretar en un texto es un determinado mundo, un mundo que yo pueda hacer mío, para proyectar en él una de mis posibilidades más propias... Es lo que yo llamo mundo del texto, el mundo propio de este texto único (p. 189).

\section{Aproximación a los derechos humanos}

La sexualidad es una dimensión del ser humano que lo abarca en su totalidad, razón por la cual los niveles que lo constituyen (físico, psíquico y espiritual), su estructura yoica y relacional y sus potencialidad están influidos por tal dimensión. "La sexualidad embrida en el ser humano tres procesos: identidad, funcionalidad y adaptación" (Meza, 2001, pp. 26-27). La identidad es la síntesis entre tradición, generación y género. La funcionalidad es la posibilidad que tiene el ser humano de relacionarse con el otro, sentir placer (erotismo) y procrear (reproducción). Y la adaptación ocurre cuando la persona logra internalizar valores, actitudes y normas para configurar el sentido de su vida. 
Con lo anterior, no resulta fácil definir la sexualidad gracias a su complejidad. Alzate (1997) la entiende como "el conjunto de condiciones estructurales, fisiológicas, comportamentales y socioculturales que permiten el ejercicio de la función sexual humana" (p.12). La función sexual nace del sustrato biológico del ser humano y está condicionada por la cultura para ser ejercida en sus modos erótico y reproductor. Así las cosas, "la sexualidad no es reductiva a la genitalidad aunque, obviamente, la considera; tampoco es un objeto que solo interesa a la biología y la medicina. Las ciencias sociales y humanas tienen una palabra qué decir al respecto" (Prada, 1992).

La salud reproductiva es definida por las Naciones Unidas como "un estado general de bienestar físico, mental y social, y no de mera ausencia de enfermedades o dolencias, en todos los aspectos relacionados con el sistema reproductivo, sus funciones y procesos" (Informe de la Conferencia Internacional sobre la Población y el Desarrollo, párrafo 7.2). En el mismo sentido, la World Association for Sexual Health -WAS, define la salud sexual de la siguiente manera:

Un estado de bienestar físico, psíquico, emocional y social en relación a la sexualidad; no es solamente la ausencia de enfermedad, disfunción o debilidad. La salud sexual requiere un enfoque respetuoso y positivo hacia la sexualidad y las relaciones sexuales, así como hacia la posibilidad de tener relaciones sexuales placenteras y seguras, libres de coerción, discriminación y violencia. Para poder alcanzar y mantener la salud sexual, los derechos sexuales de todas las personas deben ser respetados, protegidos y satisfechos (tomado de http:/ / www.worldsexology.org/).

Además, vale la pena recordar que este concepto aparece con fuerza en la Conferencia Internacional sobre Población y Desarrollo (El Cairo, 1994) con el cual se quiso ir más allá de la planificación familiar y el control de la natalidad, insistiendo en el hecho de llevar una vida sexual responsable, satisfactoria y segura, "sin olvidar la posibilidad de decidir sobre el momento y las condiciones más favorables para procrearse" (Lete y Martínez-Etayo, 2004).

Adicionalmente:

La salud reproductiva es un componente importante de la salud tanto para las mujeres como para los hombres, sin embargo, es más decisiva para las mujeres. Una parte importante de las enfermedades de las mujeres está relacionada con sus funciones y potencial reproductivos y con la forma como la sociedad las trata o maltrata por causa de su género (Cook, Dickens y Fathalla, 2005, p. 6).

Para las mujeres la salud es más que salud reproductiva. Las mujeres tienen necesidades de salud específicas relacionadas con su función sexual y reproductiva, pero además están expuestas a disfunciones sociales que causan un impacto sobre su salud física, mental o social. 
La atención en salud reproductiva se entiende como la constelación de métodos, técnicas y servicios que contribuyen a la salud y el bienestar, previniendo y resolviendo los problemas de la salud reproductiva. "También incluye la salud sexual, cuyo propósito es el mejoramiento de la vida y las relaciones personales, y no solo la asesoría y la atención relacionadas con la reproducción y las enfermedades de transmisión sexual" (Cook, Dickens y Fathalla, 2005, p. 10). La salud reproductiva no es solamente un problema importante de salud; también es un problema de desarrollo y de derechos humanos. La inequidad en la salud reproductiva es una preocupación internacional a la hora de hacer realidad la justicia social.

Finalmente, los derechos humanos, expresados en las constituciones y las leyes, y en convenciones regionales e internacionales, buscan orientar a las entidades gubernamentales y no gubernamentales, a los sujetos individuales y colectivos en una definición adecuada de sus políticas.

En general, los derechos humanos sirven para empoderar a tales sujetos porque proporcionan mecanismos que les permiten hacer valer sus intereses de manera legítima; igualmente, las entidades gubernamentales los emplean para el avance de la justicia social en la comunidad que lideran y a la que sirven, y los individuos pueden emplearlos para exigirles a las entidades gubernamentales que acaten los estándares de conducta a los cuales se han comprometido (Cook, Dickens y Fathalla, 2005, p. 143).

\section{Algunas hermenéuticas bíblicas}

Se ha superado el momento en el cual la interpretación bíblica correspondía a un determinado método o forma de llevarse a cabo. De igual modo, no se puede pensar que solo existe un ente regulador de la misma y que esa sea la única y la válida al momento de querer llegar al significado de un texto. Se debe pensar, entonces, que existen diversas posibilidades y que dentro de ellas, cada persona puede tomar la que crea más conveniente para sus intereses.

Si bien los métodos más conocidos, tal vez, son el diacrónico (elementos no simultáneos) y el sincrónico (análisis simultáneo de los signos), hoy en día se deben tener en cuenta los diversos métodos histórico-críticos de la exégesis. Esto quiere decir que se trata de ir más allá de los textos y descubrir qué hay detrás de ellos, en el pasado.

Ahora bien, para el método narrativo, el texto se convierte en el hecho que se ha vivido por y para el lector. Se podría decir, entonces, que los métodos se van a complementar, pues cada uno ofrece un aspecto a tener en cuenta lo cual va permitiendo ganar en conocimiento del texto que se tiene en frente. 
Se pueden nombrar otros métodos que, a su vez, ofrecen ópticas que permiten descubrir y poner en evidencia otros aspectos que los anteriores no ofrecen. Se puede, entonces, pensar en el método semiótico, el retórico o el feminista, por nombrar algunos más que permiten hacer ver que las miradas son variadas y ricas en aristas que se han de tener en cuenta y no olvidarlas por privilegiar una.

Según Navarro (2002), “el estudio histórico-crítico y las perspectivas sociológicas y antropológicas sitúan el trasfondo diacrónico adecuado de texto y contexto. Ahora se puede acceder a su dinámica mediante los instrumentos del análisis narrativo" (p. 73). Ahora bien se puede encontrar otro punto de vista como el de Bar-Efrat (2003) que afirma:

Los diferentes enfoques históricos han contribuido enormemente a nuestro conocimiento del mundo y de la literatura de la Biblia. No obstante, el estudio y los métodos literarios no son menos importantes que los históricos, dado que la esencia de la narrativa bíblica es tan interesante como su devenir (p. 12).

Lo anterior hace ver la necesidad de aceptar la pluralidad de métodos, si bien la lectura y la interpretación que se haga de los textos no puede ser ingenua, y debe responder a unas reglas o parámetros mínimos que la misma comunidad académica debe señalar y quien ejecuta debe respetar, de modo que poco a poco las interpretaciones se van legitimando y van ganando credibilidad.

\section{La hermenéutica positivista: el modelo univocista}

¿Cuál es la posición de dicha visión al momento de enfrentarse a un texto? "Sostiene que solo hay una interpretación válida. Las demás son en su totalidad incorrectas" (Beuchot, 2003, p. 53). Esta definición deja ver a las claras que su posición es única y verdadera, lo cual no deja espacio para ninguna otra interpretación.

Lo unívoco es lo que se predica o se dice de un conjunto de cosas en un sentido completamente idéntico, de modo que no cabe diversidad alguna entre unas y otras; por ejemplo, "Pedro, Juan, Pablo... son hombres", todos tienen que ser hombres en sentido idéntico (Beuchot, 2003, p. 45).

Dicha lectura o hermenéutica tuvo su momento histórico con el positivismo, lo que le dio fuerza y la posicionó como la lectura adecuada y la que debía seguirse por quien pretendiera acercarse a un texto si quería tener validez ante la comunidad científica. Claro que es necesario recordar que esta situación se da con la llegada de la matemática o más bien la matematización de las ciencias, lo cual hace que dicha mirada sea la única aceptada en el momento.

La formulación extrema y elaborada de esto se dio en el positivismo de este siglo, el positivismo lógico, según el cual un enunciado 
era interpretado válidamente, esto es, tenía significado y verdad, dependiendo de la experiencia. Un enunciado era significativo si había para él un adecuado procedimiento de verificación. Y la verificación era sobre todo empírica (Beuchot, 2003, p. 53).

En esta visión queda poco espacio a la participación y en realidad la posibilidad de realizar otras lecturas o interpretaciones del hecho que convoca es prácticamente nula, ante lo cual las personas no pueden reaccionar, pues dicha lectura se presenta como la única y la válida.

¿Cómo podría darse una lectura unívoca del texto de Tamar?

La historia de la sublevación de Absalón, aunque se presenta como un conjunto literaria e históricamente aislable de los demás, tiene sus raíces en los relatos anteriores. Se distingue de la historia de la guerra amonita por la vinculación tan estrecha entre las cuestiones familiares y las cuestiones políticas. Por otra parte, las cosas tienen que ser así necesariamente, ya que se trata del intento de un golpe de estado de un hijo contra su padre.

La causa lejana de la sublevación está en la situación matrimonial tan compleja de David, que fue tomando esposa según lo exigían sus desplazamientos y las circunstancias. De esta situación tenían que surgir inevitablemente rivalidades, en la medida en que la sucesión hereditaria resultaba competitiva para los diversos hijos mayores de las respectivas esposas. En este sentido, Absalón disponía de tantos derechos como podía tener Salomón o Adonías, incluso Isbaal o Meribaal...

En el punto de partida encontramos un incesto, el de Amón, hermanastro de Absalón, con su hermanastra Tamar, hermana de Absalón (2 Samuel:13). Así todo comienza y seguirá adelante durante algún tiempo como si se tratara de un triste y vulgar asunto familiar. Cuando Joad, oficial de David, negocia el indulto de Absalón después de que este hiciera matar a Amón, las cosas vuelven en un primer momento a su cauce en el círculo familiar y en el orden de las relaciones entre un padre y un hijo (Gibert, 1984, pp. 28-30).

Ahora bien, ¿de dónde se puede inferir que es una lectura unívoca? El comentario que se hace al relato bíblico no toma partido, no deja ver una posición frente a la violación, tímidamente dice: “así todo comienza y seguirá adelante durante algún tiempo como si se tratara de un triste y vulgar asunto familiar". Es aquí donde se puede apreciar que se deja pasar el hecho como si nada, nada sucedió, cuando en realidad se podría tomar más en serio todo lo sucedido. 


\section{La hermenéutica romántica: el modelo equivocista}

Al contrario de una lectura dogmática y excluyente, del otro lado se encuentra una lectura del mismo hecho que permite otras lecturas, o mejor, deja que cualquier lectura haga su aporte, lo que hace que fácilmente se llegue a un relativismo que finalmente terminará por aceptar todo lo que se presente.

La hermenéutica romántica, pues, consistía en dejarse impregnar -y no ciertamente por vía de la razón, sino por el sentimientopor el texto y su contexto, por el autor y su cultura; de alguna manera, se hacía una inmersión directa en el mundo del autor, en su cultura, se transvasaba al lector, pero de una manera que -aun cuando parecería lo más objetiva, dada esa inmersión en el otro por empatía-se realizaba por la subjetividad (Beuchot, 2003, p. 55).

Al no tener una posición o un criterio objetivo, fácilmente el lector cae en un subjetivismo que al final lo conduce a una conclusión que puede ser equívoca, pues depende mucho de los prerrequisitos que se tengan o los conocimientos con los cuales se llegue al momento del encuentro con el texto. Esta dirección conduce con seguridad a una equivocación. Luego entonces, se puede definir lo equívoco:

Lo que se predica o se dice de un conjunto de cosas en un sentido completamente diverso, de modo que una cosa no tiene conmensuración con otra; por ejemplo, cuando se dice: "el prado y el hombre ríen", lo hacen en sentidos completamente distintos (Beuchot, 2003, p. 45).

Este extremo también tiene su peligro, ya que al querer aceptar cualquier lectura o interpretación, entonces se cae en el "todo vale", que no conviene en una lectura sana de la realidad ya que deja confundidos y perplejos a quienes esperan no una sola posición, pero por lo menos una indicación firme que les permita discernir lo que se está viendo en el acontecimiento o en el hecho convocante. "La hermenéutica romántica es equivocista, da el predominio total a la diferencia, a esa diversidad de interpretaciones que introduce el yo, irrepetible e intransferible, con el peligro casi de ser incomunicable" (Beuchot, 2003, p. 57).

¿Cómo podría darse una lectura equívoca del relato de Tamar?

Presentación. Ninguna condición puede asegurar que la castidad de alguien será salvaguardada, ni la abstinencia ni vivir en presencia de familiares (Fructuoso de Braga). El caso de Amnón muestra que incluso las relaciones familiares cercanas no son ninguna salvaguardia contra la pasión ilícita (Jerónimo).

2 Samuel 13:11-14. Él la sujetó 
Vida casta. Nadie debe confiar en su castidad pasada, porque ni podrá ser más santo que David ni más sabio que Salomón, cuyos sentimientos fueron maleados por mujeres. Y para que nadie se fíe de su castidad en razón de parentesco, debe recordar que Tamar fue violada por su hermano Amnón, que se fingió enfermo. Por lo cual, los monjes y monjas deben vivir con tal castidad, que conserven la buena fama no solo ante Dios, sino también ante los hombres, y dejen a los que sobrevivan ejemplos de santidad (Fructoso de Braga, Regla general Monástica, 17).

Se abrasó en amores ilícitos. Y para que nadie confíe en el parentesco de la sangre, Amnón se abrasó en ilícitos amores hacia su hermana Tamar. Jerónimo, Cartas, 22, 12 (Franke, 2009, p. 473).

O este otro caso:

Presentación. El primer castigo divino al adulterio y asesinato de David, que inicia una serie de grandes tribulaciones, es la muerte violenta de su hijo Amnón (Salviano).

2 Samuel 13:36-38. Absalón huyó

Desgracias continuas. Estas fueron las primicias de la venganza divina; fueron las primeras, pero no las únicas. En efecto, siguió una larga serie de pruebas extraordinarias y una sucesión ininterrumpida de desgracias no se alejaron nunca de su casa. Tamar fue violada por la furiosa pasión de Amnón, y este fue matado por Absalón. Un gran crimen, en verdad, se cometió por el primero de los dos hermanos, pero el segundo se vengó todavía mucho más cruelmente. De esta manera, David su padre, fue castigado por ambos crímenes: sus dos hijos pecaron, pero los dos crímenes son la acción de tres personas: Tamar perdió la virginidad, Amnón sufrió la perdición de su asesino Absalón, que es deplorado. Ciertamente, no se sabría decir cuál de los dos hijos causó un dolor mayor a su padre, lleno de bondad: el que murió en este mundo a manos de su hermano, o el que pereció en el otro mundo por culpa de su propia mano. Salviano el Presbítero, Sobre el gobierno de Dios, 2, 5, 21 (Franke, 2009, p. 474).

Aquí se puede ver claramente una interpretación equivocista, en el sentido que cada autor da su versión de los hechos, algunas veces haciendo comentarios sobre temas, que si bien son importantes, no tocan la esencia de la violación. Se habla entonces de la castidad, de los amores ilícitos, de las penas del Rey, pero no se toca lo esencial, la violación de una mujer y las consecuencias que ello puede traer, ante todo para Tamar, pero en general para la mujer no solo de ayer, sino también de hoy. 


\section{La hermenéutica analógica-icónica}

Cuando se trata de mostrar o señalar un pensamiento, una manera de ver o de leer la realidad, se recurre a comprensiones que ayuden a tener una mirada más completa, más cierta de las que hasta ahora se han ofrecido. No se trata, entonces, de presentar la mirada o la única comprensión que se puede ofrecer. Lo que se busca es una posibilidad real de partir desde una mirada que permita condiciones de posibilidad para ver con otras ópticas lo que hasta ahora se venía leyendo con los mismos lentes y que posiblemente no permite superar límites que se han impuesto y que condicionan la vida.

Esta situación se ha presentado en las diversas disciplinas, pero aquí se quiere hacer énfasis en la teología, pues se trata de ofrecer una herramienta que permita la superación de una lectura que hasta ahora ha tenido pocas maneras de ver la realidad y, por tanto, de entenderla.

Se ha dicho que la teología ha sido ontologista, y que tiene que ser ahora hermenéutica; también se ha dicho que ha sido substancialista, y que tiene que ser ahora relacionista; pero precisamente una hermenéutica analógica servirá para darnos equilibrio en esto. Es una hermenéutica que no renuncia a la ontología, que no acaba con ella, sino la aprovecha y le confiere su lugar propio; y también pone empeño en resaltar lo relacional, por encima de lo substancial, pero sin negar la substancia, pues precisamente, la relación se da entre substancias, las relaciones necesitan de las substancias para darse; de lo que se trata es de evitar esos excesos del ontologismo y el substancialismo, y equilibrarlos mediante la analogía (Beuchot, 2006, pp. 61-62).

Es cierto que se deben respetar las diversas lecturas hasta ahora ofrecidas, pero conociéndolas, la idea es superarlas, re-interpretarlas, re-significar la realidad existente, con el único fin de superar las miradas exclusivistas y quizá dominadoras o que simplemente no quieren ver más allá de los límites por ellas impuestas.

Se presenta, entonces, la oportunidad de una posible lectura que arrojará oportunidades, horizontes, caminos nuevos de trabajo y de posibilidades para las presentes y las futuras generaciones que no se quieren quedar en las interpretaciones encerradas en viejos barriles que siguen estando allí y que tienen unos determinados códigos de lectura que se niegan a ser re-interpretados. Se busca, más bien, nuevas comprensiones, otras posibilidades que tengan como centro la persona y la sociedad, en la cual sean protagonistas la justicia y la dignidad de la vida por encima de los egoísmos individualistas. 


\section{El relato de Tamar desde la hermenéutica analógica-icónica}

Se ha de partir de mostrar el escenario del debate en el cual se ubica la propuesta hermenéutica que se desea mostrar:

Un relativismo absoluto o extremo, pues, se instala en la equivocidad. Es extremo, es pragmáticamente inconsistente, encierra contradicción performativa. Pero un absolutismo absoluto se instala en la más completa univocidad; no es autocontradictorio, pero inalcanzable para el ser humano. Sería querer conocer como a Dios, que ve todo de manera absolutamente evidente. En cambio, un relativismo relativo es analógico, y no es autorrefutante o inconsistente (Beuchot, 2003, p. 50).

Caer en un relativismo no es ninguna ganancia, pues se podría pensar que es simple proponer que todo es válido sin más y el nivel de argumentación quedaría al vaivén de lo que cada uno pueda proponer. Ahora bien, la propuesta de un relativismo con límites parece ser una propuesta más acertada, ya que no quiere ser el extremo que hasta ahora se postulaba. Es importante comprender qué se entiende por relativismo relativo:

Entendemos el relativismo relativo como un relativismo con límites, como la posibilidad de poner límites al relativismo. Hay ciertamente cosas relativas, pero hay también algunas que no lo son, que son absolutas. Esto quiere decir, en otras palabras, que no todo es relativo, a saber, que hay algunas cosas -pocas ciertamente- que son absolutas (Beuchot, 2003, p. 50).

El escenario del debate o el punto central en el cual se ubica la hermenéutica analógica, está ubicado entre dos extremos que es preciso definir de modo que haya claridad de qué trata el uno y el otro. Conocer lo que busca lo equívoco y lo análogo permite discernir y comprender la propuesta.

\section{Una antropología analógica-icónica: la persona como imagen de Dios}

Se puede partir del mismo relato bíblico que permite hacer una lectura del momento de la creación de la persona por parte de Dios:

Entonces dijo: "ahora hagamos al hombre. Se parecerá a nosotros, y tendrá poder sobre los peces, las aves, los animales domésticos y los salvajes, y sobre los que se arrastran por el suelo". Cuando Dios creó al hombre, lo creó parecido a Dios mismo; hombre y mujer los creó (Génesis 1:26-27). 
¿Cómo comprender desde la lectura analógica-icónica este relato? Lo primero que se puede notar es que las palabras "a imagen y semejanza", se pueden interpretar como lo más cercano, similar, parecido a Dios. Que en su infinito amor quiso que la persona fuera similar, no igual a él. Está una primera clave de lectura, no puede ser igual a Dios, pues sería otro Dios, pero sí puede ser semejanza suya, imagen suya, ícono suyo, para que toda la creación lograra ver en la persona la presencia de Dios.

También es necesario notar que al contemplar la naturaleza vio Dios que el hombre no tenía un complemento, y por ello, era necesaria la presencia de la mujer, que en todo era como él, pero al mismo tiempo sería su compañera de camino, junto con la que podía re-crear el mundo que Dios había hecho para la humanidad. Entonces, desde el principio, hombre y mujer fueron uno, solo que con sexo diferente, que complementa y permite ver la "gran dignidad y belleza de la sexualidad" (Beuchot, 2008, p. 100). En ningún momento se menciona la sexualidad como un obstáculo o como algo que no deba existir.

La persona misma desde el momento de la creación se convierte en un símbolo, se podría decir que cuando se logra leer lo que significa la persona en la creación de Dios, se puede ir comprendiendo el significado que el mismo Dios quiso dar a la humanidad. Es entonces, ícono de expresión de amor, pues por el amor Dios crea la naturaleza para que la humanidad la pueda disfrutar y ser junto con él co-creadores de la misma. "Pero paradójicamente también la persona es símbolo de pecado, esto quiere decir de: egoísmo, narcisismo y el espíritu de desobediencia a Dios que todos llevamos, y que empaña la imagen de Dios puesta en nosotros" (Beuchot, 2008, p. 100).

Ahora bien, al caer en egoísmo, en desobediencia, la persona se aleja de Dios, pierde su amistad. Lo cual hace que se aleje de su creador. Es gracias a Jesucristo, imagen del Padre, que la persona recupera nuevamente la posibilidad de ser nuevamente amigo de Dios.

De manera principal se habla del hombre como imagen de Dios en Jesucristo. Es mediador de muchas formas; entre ellas, la de realizar la mediación imaginal, por la que el hombre es imagen de Dios, en él, de manera perfecta, ya que es hombre y Dios. Juan lo llama 'imagen de Dios' (Juan 14:7) (Beuchot, 2008, p. 100).

\section{El concepto de persona}

Esta misma lectura analógica-icónica permite presentar un tipo de persona que a semejanza de las personas divinas, asuma una unidad y no permita una lectura que privilegie lo espiritual o lo corporal. Lo que se busca en últimas es que se siga alimentando el dualismo antropológico que ha hecho carrera en Occidente a lo largo de la historia. Se trata, entonces, de presentar la persona no solo como individuo sino al mismo tiempo como un ser social. 
El individualismo solo resalta la parte en relación con el todo, y lesiona los derechos del todo respecto de la parte, de la sociedad para con el individuo; así mismo, el totalitarismo solo resalta el todo en relación con la parte y lesiona los derechos de la parte y los derechos del todo, del individuo para con la sociedad (Beuchot, 2008, p. 197).

No se trata de olvidar al individuo, sino que se podrán aceptar escenarios en que la opción por el individuo sea legítima aun en medio de un escenario social en el que debe optarse por el individuo dada la situación en la cual se vive, por ejemplo una guerra o un momento de catástrofe. Y quien podrá orientar este momento será la prudencia o frónesis, Ciertamente en otros momentos será la sociedad la que se debe proteger en lugar de los intereses del individuo, por ello la necesidad de cultivar la prudencia, para que llegado el momento se tenga la suficiente madurez en la elección que se realice y no dejarse guiar por un individualismo y por intereses particulares.

Ahora bien, en cuanto al relato bíblico de Tamar, las mujeres del Grupo Huellas de Arte, que son quienes participan con el grupo Didaskalia de esta investigación dicen:

Mujer 1. Así como Tamar sufre el rechazo de su hermano y de la sociedad, hoy en día la mujer se ve señalada y estigmatizada cuando es diagnosticada con el VIH, entonces, se puede ver que el problema no es tanto la enfermedad, cuanto el señalamiento, el ser juzgada por quienes conviven con ella. Es tal vez, por esto, entre otras cosas que la mujer calla y prefiere seguir viviendo con quien le causa daño (entrevista realizada el 8 de febrero de 2015).

Mujer 2. Pues yo creo que ella también sufrió y sufrió más por los señalamientos que iba recibiendo, cuando dice que cuando la saque no le haga eso porque era un mal peor que lo que le había hecho antes, entonces es el que ella sufriera la violación, sí, pero sufría más por el tema de ser señalada, estigmatizada por ser sacada, humillada, por los señalamientos de los demás, creo que era en ese momento el sentimiento, pues en ese momento era más bien el tema de que ella era la que iba a ser juzgada y no por el hecho del abuso, cuando ella acepta que ese es el peor sufrimiento que le puede causar y lo pone por encima del abuso sexual, entonces a ella lo que más le afectaba era que la sacara a fuerza de su casa y la dejara en la calle, entonces es como vemos ahora muchas mujeres aceptan que sus parejas abusen sexualmente de ellas pero por eso mismo, porque si las sacan o se van no tienen a dónde ir y van a ser señaladas, entonces esa es la aceptación y naturalización que se ve (entrevista realizada el 8 de febrero de 2015).

Es necesario y urgente una toma de partido a favor de la mujer, pero sería mucho más significativo si fueran los mismos hombres los que llevarán a cabo esta acción, pues se trata de romper el patriarcado y darles su debido valor. Esto quiere 
decir que debe ser el hombre quien tome la bandera y ayude a la liberación de la mujer, para que su voz no siga siendo callada y silenciada por la sociedad.

Mujer 3. También se observan las acciones violentas, se evidencia que aun en nuestro medio y en el día a día vemos que aún está muy fuerte la parte patriarcalizada en el hombre, entonces: cállate porque es tu hermano y es de cuidar; así es que se protege al agresor (entrevista realizada el 8 de febrero de 2015).

Mujer 4. Eso se ve en estos momentos en la vida diaria, que a pesar de que ella manifestaba que no abusara de ella, que no lo hiciera, no importa cómo le suplicó. Eso se ve a diario, no interesa las condiciones como la mujer quede o como se encuentre y la vida continúa, pasa desapercibida (entrevista realizada el 8 de febrero de 2015).

Sin lugar a dudas, el poder y la autoridad se han unido para silenciar a la mujer, pues cuando algo sucede no hay justicia, se le hace aparte y se le calla, algunas veces con mayor violencia que la que se ejerce contra su cuerpo. De allí la necesidad de darle voz a la mujer, de permitirle que verbalice lo que está sucediendo de manera que se sienta escuchada y atendida en sus necesidades $\mathrm{y}$ en sus peticiones.

Mujer 5. No, el tema es de poder ella también, pues cómo iba a hablar si era el primogénito del rey y era más importante el tipo este pues era quien iba a suceder al rey David, y ella pues simplemente la hija mujer que era relegada casi a lo que menos valía en esa estructura familiar (entrevista realizada el 8 de febrero de 2015).

Se puede notar una lectura que no es ni unívoca, ni equívoca, que parte de la realidad vivida, de una interpretación que tiene en cuenta la experiencia humana de quien debe vivir la vida y la cotidianidad desde los acontecimientos, no solo desde las bases teóricas y científicas, sino teniendo que habérselas con la vida misma en realidades concretas.

Las mujeres expresan su vivencias, pero también las esperanzas y las perspectivas que hoy ofrece el texto, se mueven dentro del relato, pero de inmediato vienen al aquí y al ahora, a la vida misma, a la experiencia vivida. Es muy importante notar ese ir al texto y volver a la realidad, lo cual permite actualizar el texto, leerlo desde el hoy y permitir que esa experiencia deje una enseñanza para superar lo que hoy también está pasando por otras realidades y contextos. 


\section{Referencias}

Alzate, H. (1997). Sexualidad humana. Bogotá: Temis.

Bar-Efrat, S. (2003). El arte de la narrativa en la Biblia. Madrid: Cristiandad.

Beuchot, M. (2003). Hermenéutica analógica. Aplicaciones en América Latina. Bogotá: El Búho.

Beuchot, M. (2008). Hermenéutica analógica-icónica y teología. Colección Teología Hoy, (67). Bogotá: Pontificia Universidad Javeriana, Facultad de Teología.

Cook, R., Dickens, B. y Fathalla, M. (2005). Salud reproductiva y derechos humanos: integración de la medicina, la ética y el derecho. Bogotá: Oxford-Profamilia.

Franke, J. (Editor general) (2009). La Biblia comentada por los Padres de la Iglesia y otros autores de la época patrística. Josué, Jueces, Rut, 1-2 Samuel. Antiguo Testamento, 4. Madrid: Ciudad Nueva.

Lete, I. y Martínez-Etayo, M. (2004). La salud reproductiva: datos y reflexiones. Gaceta Sanitaria [online], 1(18), 170-174. Recuperado de http://scielo.isciii. es/scielo.php?script=sci_arttext\&pid=S0213-91112004000400027\&lng=es\& nrm=iso. ISSN 0213-9111

Meza, J. (2001). La afectividad y la sexualidad en la vida religiosa. Bogotá: Indoamerican.

Navarro, M. (2002). Análisis narrativo de Mc 5, 1-20. Aguirre, R. Los milagros de Jesús, perspectivas metodológicas plurales. Estrella: Verbo Divino.

Prada, R. (1992). Sexualidad y amor. Bogotá: Paulinas. 